\title{
Age-Related Association of Calcitonin with Parameters of Anthropometry, Bone and Calcium Metabolism during Childhood
}

\author{
Juliane Sonntag ${ }^{\mathrm{a}} \quad$ Mandy Vogel $^{\mathrm{a}} \quad$ Mandy Geserick $^{\mathrm{a}} \quad$ Felix Eckelt $^{\mathrm{b}}$ \\ Antje Körner ${ }^{a, c}$ Friedhelm Raue ${ }^{d}$ Wieland Kiess $^{a, c}$ Jürgen Kratzsch ${ }^{b}$ \\ aLIFE Leipzig Research Center for Civilization Diseases, University of Leipzig, Leipzig, Germany; ${ }^{b}$ Institute for \\ Laboratory Medicine, Clinical Chemistry and Molecular Diagnostics (ILM), University Hospital Leipzig, Leipzig, \\ Germany; ${ }^{C H}$ ospital for Children and Adolescents, Center of Pediatric Research, University of Leipzig, Leipzig,

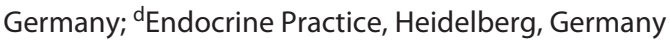

\author{
Keywords \\ Calcitonin - Calcium homeostasis · Bone metabolism · \\ Growth
}

\begin{abstract}
Introduction: The thyroid parafollicular hormone calcitonin (CT) shows particularly high blood levels in early childhood, a period of high bone turnover, which decrease with increasing age. Data about the physiological role of $\mathrm{CT}$ during infancy, childhood, and adolescence are contradictory or lacking. Objective: We hypothesize that CT demonstrates agerelated correlations with parameters of bone growth and turnover as well as with parameters of calcium homeostasis. Methods: 5,410 measurements of anthropometric data and venous blood samples were collected from 2,636 participants of the LIFE Child study, aged 2 months- 18 years. Univariate correlations and multiple regression analysis were performed between serum CT and anthropometric indicators (height standard deviation scores [SDS] and BMI-SDS), markers of calcium (Ca) homeostasis ( $\mathrm{Ca}$, parathyroid hormone, 25-OH vitamin $\mathrm{D}$, and phosphate [P]), bone formation (procollagen type $1 \mathrm{~N}$-terminal propeptide [P1NP], osteocalcin), and bone resorption ( $\beta$-CrossLaps). Results: CT was sig-
\end{abstract}

nificantly associated with $\mathrm{Ca}(\beta=0.26, p<0.05)$ and $\mathrm{P} 1 \mathrm{NP} / 100$ $(\beta=0.005, p<0.05)$ in children aged 2 months-1.1 years. These relations were independent of age and sex and could not be confirmed in children aged 1.1-8 years. Independent of age, sex, puberty, $P$, and height SDS CT showed a significant positive relation to $\mathrm{Ca}(\beta=0.26 ; p<0.001)$ in children aged $8-18$ years. Conclusions: Our findings suggest a unique association between $\mathrm{CT}$ and $\mathrm{Ca}$ in periods of rapid bone growth and point to a possible involvement of $\mathrm{CT}$ in promoting bone formation during the first year of life.

(c) 2020 The Author(s)

Published by S. Karger AG, Basel

\section{Introduction}

Calcitonin (CT) is a peptide hormone which is produced by the C-cells of the thyroid gland. The release of CT is stimulated by an acute rise in serum calcium $(\mathrm{Ca})$ levels $[1,2]$.

The biological effect of CT is to maintain Ca homeostasis together with parathyroid hormone (PTH) and vitamin D as it lowers the elevated blood Ca concentration [2] due to its inhibitory effect on bone resorption medi- karger@karger.com www.karger.com/hrp

Karger $\stackrel{\text { ' }}{5}$

GOPEN ACCESS
(C) 2020 The Author(s)

Published by S. Karger AG, Basel

This is an Open Access article licensed under the Creative Commons Attribution-NonCommercial-4.0 International License (CC BY-NC) (http://www.karger.com/Services/OpenAccessLicense), applicable to the online version of the article only. Usage and distribution for commercial purposes requires written permission.
Jürgen Kratzsch

Institute of Laboratory Medicine, Clinical Chemistry and Molecular Diagnostics University Hospital of Leipzig, Paul-List-Str. 13/15

DE-04103 Leipzig (Germany)

Juergen.Kratzsch@medizin.uni-leipzig.de 
ated by osteoclasts [3-6]. Friedman and Raisz [5] who cultured bone shafts of rat embryos in a medium with CT observed a suppression of bone resorption after adding PTH. Furthermore, CT acts on kidney by not only increasing $\mathrm{Ca}$ and phosphate $(\mathrm{P})$ excretion [7] but also by stimulating 1,25-dihydroxyvitamin $\mathrm{D}_{3}$ production [8]. Davey and Findlay [9] suggest 2 roles for CT: regulation of first bone turnover to protect the skeleton and second of Ca homeostasis.

There is only poor evidence for the assumption that CT could act strongly age-dependent. Cooper et al. [10] discovered a more pronounced effect of CT on serum $\mathrm{Ca}$ in rats 5 weeks old compared to older rats. Moreover, an indirect clue for an age-dependent functional role of CT was the observation of a 5 -fold decrease in serum CT from the neonatal period to adolescence [11].

Concomitant with the age dependency, CT effects appear to be dependent on bone turnover rate: In healthy human adults who have physiologically distinctly lower rates of bone turnover than children no effect of CT injection on serum Ca level was found [7]. Interestingly, neither thyroidectomized patients without detectable CT nor patients with medullary thyroid carcinoma (MTC) and high CT blood levels revealed a disturbance of their skeletal homeostasis $[9,12]$. However, in states of high rates of bone turnover we hypothesize that CT responds to changes of serum biomarkers for bone formation as osteocalcin (OC) and procollagen type $1 \mathrm{~N}$-terminal propeptide (P1NP) as well as to changes of $\beta$-CrossLaps (BCL) that reflects bone resorption. In adults with an increased bone turnover derived from a thyrotoxicosis or Paget's disease the administration of CT leads to the reduction of bone resorption and lower plasma Ca level [7, 13].

Infants and children, especially within the first years of life and during puberty demonstrated a higher bone metabolism than in later life [14] and therefore we assume that their CT values were functionally regulated. Data about the biological effect of CT and about the underlying mechanism for its upregulation during infancy were contradictory or lacking so far. Furthermore, most of the studies which had a focus on the physiology and pathophysiology of CT in childhood were published in the 1970s and 1980s with only a small number of subjects. Previous findings should be reevaluated given the availability of improved immunoassays for measuring CT.

Accordingly, we hypothesize that CT is age-dependently involved in (1) growth, (2) Ca homeostasis, and (3) bone turnover of infants and children. Therefore, we investigated if the specific biomarkers (1) height standard deviation scores (SDS) and BMI-SDS; (2) Ca, PTH, 25$\mathrm{OH}$ vitamin $\mathrm{D}$ (25OHD), and $\mathrm{P}$ as well as (3) OC and $\mathrm{P} 1 \mathrm{NP}$ and BCL are correlated to serum CT levels in different age groups.

\section{Materials and Methods}

\section{Research Design and Participants}

Infants, children, and adolescents of the LIFE Child study, a population-based longitudinal cohort study at the Leipzig Research Center for Civilization Diseases, were included into our investigations between 2011 and 2017. Additional information can be found in Poulain et al. [15] and Quante et al. [16].

Exclusion criteria were endocrine disorders; diseases of bone and muscles, of kidney and liver, of the cardiovascular system, of the gastrointestinal tract; coagulation disorders, and mental illnesses. Subjects taking drugs interfering with hormonal or bone metabolism were also excluded. As a result, the study cohort consisted of 2,636 participants aged approximately 2 months -18 years (1,236 females and 1,400 males) with 5,410 measurements $(2,486$ females and 2,924 males). The cohort was divided into 4 prepubertal age groups: (1) 2 months-1.1 years; (2) 1.1-4 years; (3) 4-6 years; (4) 6-8 years and into 5 pubertal stage-dependent subgroups (aged 8-18 years). Detailed numbers of subjects are shown within tables and figures. The first age group was extended to the age limit of 1.1 instead of 1 year due to the allowed age range of the 1 -year visit date within our study (1 year \pm 1 month).

\section{Anthropometric Measurements}

Anthropometric data were collected by trained and certified study assistants following a standardized protocol. For the calculation of BMI, the following formula was used: bodyweight (kg) divided by height $\left(\mathrm{m}^{2}\right)$. Age- and sex-specific SDS values of height and BMI were calculated according to tables of Kromeyer-Hauschild et al. [17]. Pubertal status was evaluated under the terms of Tanner stages $(\mathrm{I}-\mathrm{V})[18,19]$.

\section{Laboratory Parameter}

CT, P1NP, OC, 25OHD, BCL, and PTH were measured using the Cobas ECLIA system (electrochemiluminescence immunoassay method, Cobas, Roche, Mannheim) method. Levels of total Ca were quantified by photometric color tests, $\mathrm{P}$ was measured by a photometric UV test by the Cobas clinical chemistry unit. Coefficients of variations for measurements of the same patients' sera were published recently [20,21].

\section{Statistical Analysis}

All data were processed using R [22] version 3.3.3 (2017-03$06)$. Descriptive statistics were given as mean and standard deviation. Due to considerable skewness, CT was log-transformed $(\log C T)$. Univariate relationships were estimated using Spearman's rank correlation coefficient. In correlation analyses only the first measurement per child was considered.

Multivariable relationships were estimated applying linear mixed effect models as implemented in the lme4 package [23]. To account for multiple measurements per subject, the subject was included as random intercept. All models were adjusted for age and sex. The $p$ values were estimated using normal approximation 
Table 1. Characteristics of anthropometric and biochemical data on the study cohort (mean values \pm standard deviation) in age-related subgroups

\begin{tabular}{|c|c|c|c|c|c|}
\hline & \multicolumn{5}{|l|}{ Age range } \\
\hline & $0.17-1.1$ years & $>1.1-4$ years & $>4-6$ years & $>6-8$ years & $>8-18$ years \\
\hline \multicolumn{6}{|l|}{ Boys } \\
\hline Age, years & $0.56 \pm 0.31$ & $2.66 \pm 0.72$ & $5.00 \pm 0.60$ & $7.02 \pm 0.60$ & $12.2 \pm 2.58$ \\
\hline Height, $\mathrm{cm}$ & $68.8 \pm 6.42$ & $93.2 \pm 7.49$ & $111 \pm 6.01$ & $126 \pm 6.27$ & $157 \pm 16.6$ \\
\hline Height SDS & $0.34 \pm 1.00$ & $-0.11 \pm 0.97$ & $-0.01 \pm 0.96$ & $0.25 \pm 0.95$ & $0.28 \pm 1.01$ \\
\hline BMI, kg/m² & $16.4 \pm 1.28$ & $16.2 \pm 1.29$ & $15.5 \pm 1.21$ & $16.0 \pm 2.42$ & $19.5 \pm 4.32$ \\
\hline BMI-SDS & $-0.07 \pm 0.95$ & $0.23 \pm 0.85$ & $-0.05 \pm 0.79$ & $-0.04 \pm 1.04$ & $0.19 \pm 1.14$ \\
\hline $\mathrm{CT}, \mathrm{ng} / \mathrm{L}$ & $13.8 \pm 7.64$ & $6.13 \pm 3.50$ & $5.01 \pm 2.75$ & $4.69 \pm 2.85$ & $3.17 \pm 2.46$ \\
\hline $\log C T, n g / L$ & $1.07 \pm 0.25$ & $0.72 \pm 0.25$ & $0.64 \pm 0.24$ & $0.59 \pm 0.27$ & $0.36 \pm 0.38$ \\
\hline Calcium, mmol/L & $2.59 \pm 0.09$ & $2.46 \pm 0.08$ & $2.45 \pm 0.08$ & $2.45 \pm 0.08$ & $2.46 \pm 0.09$ \\
\hline Phosphate, $\mathrm{mmol} / \mathrm{L}$ & $1.84 \pm 0.17$ & $1.65 \pm 0.15$ & $1.57 \pm 0.12$ & $1.54 \pm 0.13$ & $1.47 \pm 0.18$ \\
\hline $\mathrm{PTH}, \mathrm{pmol} / \mathrm{L}$ & $2.61 \pm 1.27$ & $2.99 \pm 1.00$ & $3.03 \pm 1.00$ & $3.02 \pm 0.96$ & $3.45 \pm 1.26$ \\
\hline $25 \mathrm{OHD}, \mathrm{ng} / \mathrm{mL}$ & $43.6 \pm 16.2$ & $26.3 \pm 12.2$ & $23.4 \pm 10.6$ & $24.0 \pm 9.44$ & $22.6 \pm 10.3$ \\
\hline $\mathrm{P} 1 \mathrm{NP}, \mathrm{ng} / \mathrm{mL}$ & $1,724 \pm 747$ & $651 \pm 186$ & $599 \pm 152$ & $567 \pm 144$ & $627 \pm 295$ \\
\hline $\mathrm{OC}, \mathrm{ng} / \mathrm{mL}$ & $123 \pm 42.1$ & $73.4 \pm 20.7$ & $81.8 \pm 19.4$ & $86.7 \pm 19.5$ & $113 \pm 45.7$ \\
\hline $\mathrm{BCL}, \mathrm{pg} / \mathrm{mL}$ & $1,027 \pm 206$ & $1,126 \pm 335$ & $1,458 \pm 356$ & $1,517 \pm 344$ & $1,778 \pm 548$ \\
\hline \multicolumn{6}{|l|}{ Girls } \\
\hline Age, years & $0.56 \pm 0.30$ & $2.72 \pm 0.72$ & $5.04 \pm 0.62$ & $7.04 \pm 0.56$ & $12.4 \pm 2.53$ \\
\hline Height, $\mathrm{cm}$ & $66.9 \pm 6.43$ & $92.4 \pm 7.31$ & $110 \pm 6.28$ & $125 \pm 6.68$ & $154 \pm 13.2$ \\
\hline Height SDS & $0.16 \pm 1.02$ & $-0.17 \pm 0.93$ & $-0.21 \pm 0.87$ & $0.14 \pm 1.01$ & $0.17 \pm 0.95$ \\
\hline BMI, kg/m² & $15.8 \pm 1.23$ & $16.0 \pm 1.22$ & $15.4 \pm 1.40$ & $16.1 \pm 2.64$ & $20.2 \pm 4.89$ \\
\hline BMI-SDS & $-0.14 \pm 0.92$ & $0.16 \pm 0.81$ & $-0.08 \pm 0.83$ & $0.03 \pm 1.04$ & $0.29 \pm 1.21$ \\
\hline $\mathrm{CT}, \mathrm{ng} / \mathrm{L}$ & $12.6 \pm 7.22$ & $4.58 \pm 2.69$ & $3.38 \pm 2.16$ & $3.10 \pm 1.91$ & $1.72 \pm 1.73$ \\
\hline $\log \mathrm{CT}, \mathrm{ng} / \mathrm{L}$ & $1.03 \pm 0.26$ & $0.59 \pm 0.26$ & $0.44 \pm 0.30$ & $0.40 \pm 0.31$ & $0.06 \pm 0.38$ \\
\hline Calcium, mmol/L & $2.62 \pm 0.08$ & $2.49 \pm 0.08$ & $2.48 \pm 0.08$ & $2.47 \pm 0.08$ & $2.45 \pm 0.09$ \\
\hline Phosphate, mmol/L & $1.85 \pm 0.16$ & $1.64 \pm 0.15$ & $1.60 \pm 0.11$ & $1.54 \pm 0.12$ & $1.41 \pm 0.18$ \\
\hline $\mathrm{PTH}, \mathrm{pmol} / \mathrm{L}$ & $2.79 \pm 1.38$ & $3.31 \pm 1.33$ & $3.35 \pm 1.10$ & $3.45 \pm 1.14$ & $3.67 \pm 1.27$ \\
\hline $25 \mathrm{OHD}, \mathrm{ng} / \mathrm{mL}$ & $43.3 \pm 16.7$ & $25.1 \pm .11 .9$ & $23.7 \pm 10.8$ & $23.0 \pm 8.97$ & $21.5 \pm 9.73$ \\
\hline $\mathrm{P} 1 \mathrm{NP}, \mathrm{ng} / \mathrm{mL}$ & $1,649 \pm 607$ & $655 \pm 179$ & $620 \pm 145$ & $607 \pm 165$ & $485 \pm 291$ \\
\hline $\mathrm{OC}, \mathrm{ng} / \mathrm{mL}$ & $116 \pm 39.6$ & $78.8 \pm 21.5$ & $89.0 \pm 22.4$ & $96.7 \pm 24.5$ & $93.4 \pm 43.5$ \\
\hline $\mathrm{BCL}, \mathrm{pg} / \mathrm{mL}$ & $1,026 \pm 220$ & $1,097 \pm 328$ & $1,494 \pm 386$ & $1,534 \pm 407$ & $1,430 \pm 544$ \\
\hline
\end{tabular}

$N$ (boys, aged $0.17-8$ years): $\geq 241 ; n$ (boys, aged $>8-18$ years): $\geq 1,516 ; n$ (girls, aged $0.17-8$ years): $\geq 156 ; n$ (girls, aged >8-18 years): $\geq 1,306$. CT, calcitonin; SDS, standard deviation score; log, logarithmized; PTH, parathyroid hormone; 25OHD, 25-hydroxyvitamin D; P1NP, procollagen type $1 \mathrm{~N}$-terminal propeptide; OC, osteocalcin; BCL, $\beta$-CrossLaps.

as implemented in the multcomp package [24]. All $p$ values were corrected for multiple testing using the method of controlling for the false discovery rate [25]. Statistical tests with $p$ values $<0.05$ were considered as statistically significant.

\section{Results}

Characteristics of the Study Population (Age: 2 months-18 years)

We included laboratory and anthropometric parameters of a total amount of 5,410 measurements (2,924 boys and 2,486 girls) (Table 1). As expected, the mean CT values (and mean $\log$ CT values) were higher in boys compared to the girls in all age groups. Overall, the boys were on average 0.3 years younger than the girls (boys $=8.78$ years, girls $=9.08$ years); height SDS was +0.22 in boys versus +0.10 in girls and BMI-SDS +0.12 in boys versus +0.18 in girls.

\section{Univariate Correlation Analysis}

Anthropometric Parameter versus CT

As hypothesized, height SDS was positively associated with CT in children aged 2 months- 1.1 years but reached 
Table 2. Univariate correlations of CT with markers of anthropometry, calcium homeostasis, and bone metabolism within the study cohort in age-related subgroups

\begin{tabular}{|c|c|c|c|c|}
\hline & \multicolumn{4}{|l|}{ Age range $^{\mathrm{x}}$} \\
\hline & $\begin{array}{l}\text { rho }^{\mathrm{a}} \\
(0.17-1.1 \text { years; b/g) }\end{array}$ & $\begin{array}{l}\text { rho }^{\mathrm{a}} \\
(1.1-4 \text { years; b/g) }\end{array}$ & $\begin{array}{l}\mathrm{rho}^{\mathrm{a}} \\
(>4-6 \text { years; b/g) }\end{array}$ & $\begin{array}{l}\text { rho }^{\mathrm{a}} \\
(>6-8 \text { years; b/g) }\end{array}$ \\
\hline \multicolumn{5}{|l|}{ Anthropometry } \\
\hline Age & $-0.53^{* * *} /-0.65^{* * *}$ & $-0.21^{* *} /-0.30^{* * *}$ & $0.07 /-0.08$ & $-0.02 /-0.01$ \\
\hline Height SDS & $0.16 * / 0.09$ & $-0.11 /-0.05$ & $-\mathbf{0 . 2 0 * *} /-0.10$ & $-\mathbf{0 . 1 6} * /-0.12$ \\
\hline BMI-SDS & $\mathbf{0 . 2 3} 3^{* *} / 0.09$ & $0.13 / 0.09$ & $-0.08 / 0.11$ & $-0.13 / 0.02$ \\
\hline \multicolumn{5}{|c|}{ Calcium homeostasis } \\
\hline Calcium & $0.25^{* *} / 0.13$ & $0.04 / 0.04$ & $-0.02 /-0.07$ & $-0.03 /-0.00$ \\
\hline Phosphate & $0.15 / 0.17$ & $-0.03 / 0.15$ & $-\mathbf{0 . 1 8} * /-0.07$ & $-0.03 /-0.15^{*}$ \\
\hline PTH & $-0.22^{*} /-0.37^{* * *}$ & $-0.03 / 0.08$ & $0.02 / 0.06$ & $0.13 / 0.02$ \\
\hline $25 \mathrm{OHD}$ & $-0.17 / 0.04$ & $-0.00 / 0.02$ & $0.04 / 0.15$ & $-0.00 / 0.08$ \\
\hline \multicolumn{5}{|l|}{ Bone markers } \\
\hline P1NP & $0.50^{* * *} / 0.42^{* * *}$ & $-0.02 /-0.08$ & $-0.10 /-0.05$ & $-0.14 / 0.03$ \\
\hline $\mathrm{OC}$ & $0.36^{* * *} / 0.35^{* * *}$ & $-0.10 /-0.07$ & $-0.16 * /-0.03$ & $-0.12 /-0.02$ \\
\hline BCL & $0.00 / 0.06$ & $-0.13 /-0.07$ & $-0.15 /-0.02$ & $-0.08 /-0.09$ \\
\hline
\end{tabular}

Results of boys and girls were shown separately (b/g). For all subgroups, $n=106-263$. All significant correlation coefficients are marked in bold. CT, calcitonin; SDS, standard deviation score; PTH, parathyroid hormone; 25OHD, 25-hydroxyvitamin D; P1NP, procollagen type $1 \mathrm{~N}$-terminal propeptide; OC, osteocalcin; BCL, $\beta$-CrossLaps. ${ }^{*} p<0.05$. ${ }^{* *} p<0.01$. ${ }^{* * *} p<0.001$. $^{\mathrm{a}}$ Indicates Spearman's rank coefficient. ${ }^{\mathrm{x}}$ The univariate correlations of the age group $8-18$ years can be found in the supplement.

significance only in boys. In contrast, a significantly negative association was found in boys aged $4-6$ years and $6-8$ years (Table 2 ) and in boys and girls aged $8-18$ years (online suppl. Table 5; for all online suppl. material, see www.karger.com/doi/10.1159/000512107). BMI-SDS was significantly positively correlated with CT in boys aged 2 months- 1.1 years. In contrast, 8 - to 18 -year-old children and adolescents showed a significantly negative correlation.

\section{Calcium Homeostasis versus CT}

In boys aged 2 months- 1.1 years we detected a positive and significant correlation between Ca and CT (Table 2). In girls of the same age the correlation was also positive but did not reach significance $(p=0.17)$. Likewise, girls aged $8-18$ years Ca showed a positive and significant correlation with CT while this correlation was significantly negative in same-aged boys (online suppl. Table 5). P was significantly negatively associated with CT in boys aged $4-6$ years and girls aged $6-8$ years and significantly positively in girls aged 8-18 years. In the age group 2 month-1.1 years PTH was also significantly negatively correlated with $\mathrm{CT}$ and $\mathrm{Ca}$ in both sexes but we did not find any significant correlations in older children. In the pubertal group 25OHD showed a positive and significant correlation with CT in both sexes.

\section{Bone Markers versus CT}

We found significantly positive correlations of P1NP and $\mathrm{OC}$ with $\mathrm{CT}$ in boys and girls aged 2 months-1.1 years (Table 2 ) and a significantly negative correlation between OC and CT in boys aged 4-6 years. In the pubertal group there was a switch to significantly negative correlations of P1NP, OC, and BCL with CT in boys while these correlations were significantly positive in girls (online suppl. Table 5).

\section{Multiple Regression Analysis}

After adjustment for age and sex, from the anthropometric parameters, height-SDS remained independently negatively correlated in age groups $4-6$ years and 6-8 years. BMI-SDS was significantly positively correlated in children aged 1.1-4 years and significantly negatively correlated in the age group 6-8 years (Table 3 ).

In the group of parameters of the Ca homeostasis the positive correlation between $\mathrm{CT}$ and $\mathrm{Ca}$ in the group 2 
Table 3. Multiple linear regression of CT levels of the study cohort with markers of anthropometry, calcium homeostasis, and bone metabolism adjusted for age and sex (and for the age group 8-18 also for puberty) in agerelated subgroups

\begin{tabular}{|c|c|c|c|c|c|}
\hline & \multicolumn{5}{|l|}{ Age range } \\
\hline & $\begin{array}{l}\beta^{\mathrm{b}} \\
0.17-1.1 \text { years }\end{array}$ & $\begin{array}{l}\beta^{\mathrm{b}} \\
>1.1-4 \text { years }\end{array}$ & $\begin{array}{l}\beta^{\mathrm{b}} \\
>4-6 \text { years }\end{array}$ & $\begin{array}{l}\beta^{\mathrm{b}} \\
>6-8 \text { years }\end{array}$ & $\begin{array}{l}\beta^{\mathrm{b}} \\
>8-18 \text { years }\end{array}$ \\
\hline \multicolumn{6}{|l|}{ Anthropometry } \\
\hline Height SDS & -0.02 & -0.01 & $-0.05^{* * *}$ & $-0.04^{* * *}$ & $-0.06^{* * *}$ \\
\hline BMI-SDS & 0.01 & 0.03* & 0.01 & $-0.02 *$ & $-0.04^{* * *}$ \\
\hline \multicolumn{6}{|c|}{ Calciumhomeostasis } \\
\hline Calcium & $0.24^{*}$ & 0.13 & 0.12 & 0.08 & $0.17^{* *}$ \\
\hline Phosphate & 0.08 & -0.08 & -0.17 & $-0.18^{*}$ & $-0.22^{* * *}$ \\
\hline $\mathrm{PTH}$ & -0.01 & 0.01 & -0.01 & 0.003 & $-0.01 *$ \\
\hline $25 \mathrm{OHD}$ & -0.0004 & -0.0002 & 0.001 & 0.001 & $0.002^{* * *}$ \\
\hline \multicolumn{6}{|l|}{ Bone markers } \\
\hline $\mathrm{P} 1 \mathrm{NP} / 100$ & $0.004^{*}$ & $-0.01^{*}$ & $-0.02 *$ & -0.01 & $-0.01^{* * *}$ \\
\hline $\mathrm{OC}$ & $0.001 *$ & -0.001 & -0.0005 & -0.0004 & $-0.0009^{* * *}$ \\
\hline BCL & $-4 \times 10^{-5}$ & $-3 \times 10^{-5}$ & $-4 \times 10^{-5}$ & $-3 \times 10^{-7}$ & $-7 \times 10^{-5 * * *}$ \\
\hline
\end{tabular}

CT, calcitonin; SDS, standard deviation score; PTH, parathyroid hormone; 25OHD, 25-hydroxyvitamin D; P1NP, procollagen type $1 \mathrm{~N}$-terminal propeptide; OC, osteocalcin; BCL, $\beta$-CrossLaps. $n$ for the subgroups 0.17 8 years $=402-635 ; n$ for those $>8-18$ years $=2,072-2,368$. All significant regression coefficients are marked in bold. ${ }^{*} p<0.05$. ${ }^{* *} p<0.01$. ${ }^{* * *} p<0.001{ }^{\mathrm{b}}$ Indicates the regression coefficients (regression coefficients are adjusted for age and sex (for the age group 8-18 also for pubertal stages).

months-1.1 years was still significant (Fig. 1). In 6-8 years old children the correlation between $\mathrm{P}$ and $\mathrm{CT}$ was significantly negative.

From the bone markers the positive correlation of OC and P1NP with CT continued to be significant in children aged 2 months-1.1 years. In children aged 1.1-6 years there was a significantly negative correlation between CT and P1NP.

In the age group 8-18 years CT was significantly positively associated with calcium and 25OHD and significantly negatively with height-SDS, BMI-SDS, P, PTH, P1NP, osteocalcin, and BCL after adjusting for age, sex, and puberty.

\section{Combined Multiple Linear Regression Model}

After including all significantly associated parameters (age- and sex-adjusted models) in a final model, we found significantly positive correlations of $\mathrm{Ca}$ and $\mathrm{P} 1 \mathrm{NP}$ with CT in the age group 2 months-1.1 years (Table 4 ).

For the age group 6-8 years negative correlations remained significant for height SDS $\left(\beta=-0.04^{* *}\right)$ and $\mathrm{P}$ $\left(\beta=-0.18^{*}\right)$ after the inclusion of age, sex, height SDS, and $\mathrm{P}$ as independent variables.

For the group of 8-18-year-old subjects, the final model included age, sex, Ca, P, height SDS, and pubertal stag-

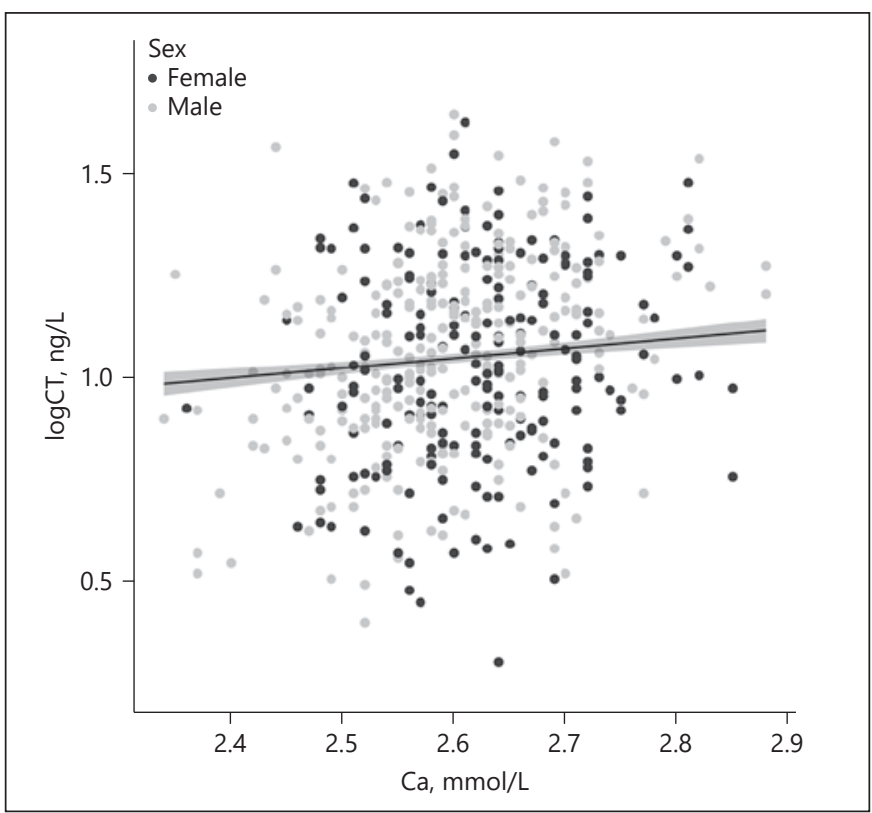

Fig. 1. Data of $\log C \mathrm{~T}$ versus calcium $(\mathrm{Ca})$ in the age group of 2 months-1.1 years adjusted for age and sex (multiple measurements per subject were considered). The solid line characterizes the $\log$ CT versus calcium relationship: $\beta=0.24^{*}(p<0.05)$. The grey area defines the standard error. $n$ (boys) $=280$ and $n$ (girls) $=$ 195. CT, calcitonin; log, logarithmized. 


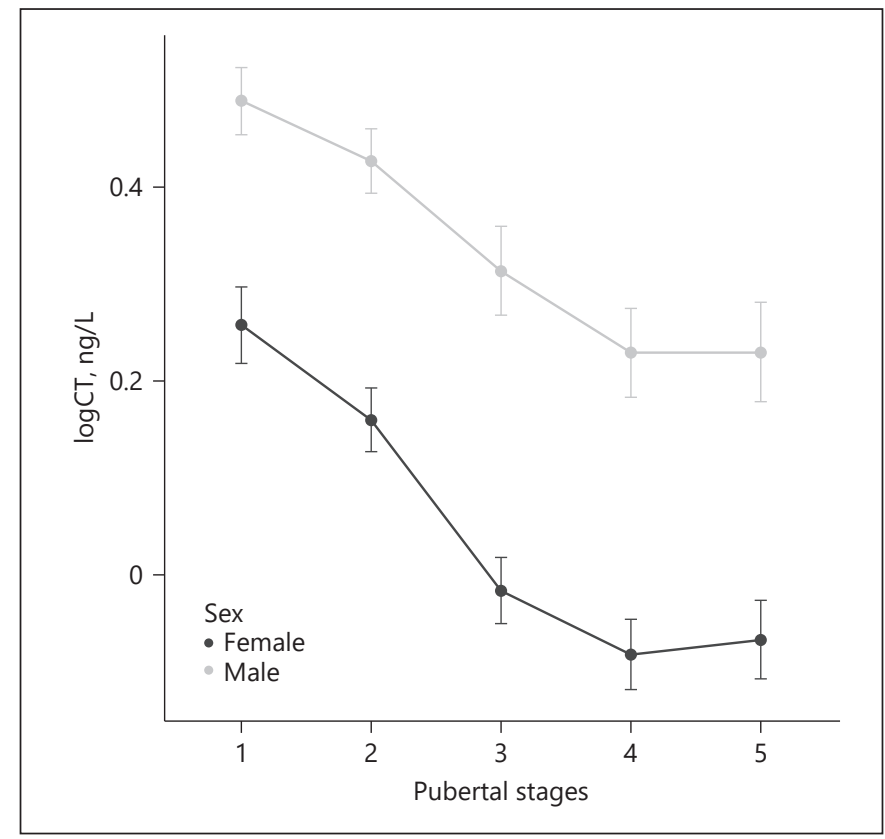

Fig. 2. Mean logCT levels during puberty adjusted for age, phosphate, calcium, height SDS, pubertal stages and stratified by sex (8-18 years). Shown are the $95 \%$ confidence intervals. Pubertal stages were evaluated according to Tanner. $n$ (boys) $=1,054$ and $n$ (girls) $=1,263$. CT, calcitonin; log, logarithmized; SDS, standard deviation scores.

Table 4. Combined multiple linear regression model for children in the age between 2 months and 1.1 years

\begin{tabular}{ll}
\hline & $\beta^{\mathrm{b}}(n=462)$ \\
\hline Age & $\mathbf{- 0 . 3 6}^{* * *}$ \\
Sex $\left(\right.$ male $\left.^{\mathrm{c}}\right)$ & 0.04 \\
Calcium & $\mathbf{0 . 2 6}^{*}$ \\
P1NP/100 & $\mathbf{0 . 0 0 5}^{*}$ \\
\hline
\end{tabular}

Age, sex, calcium, and P1NP were included as independent variables for CT as dependent variable. $\mathrm{P} 1 \mathrm{NP}$, procollagen type 1 $\mathrm{N}$-terminal propeptide. All significant regression coefficients are marked in bold. ${ }^{*} p<0.05$. $^{* *} p \leq 0.001$. $^{\mathrm{b}}$ Indicates the regression coefficient. ${ }^{c}$ Girls $=$ reference.

es as predictors. CT levels significantly decreased with advancing Tanner stages until stage 4 in both sexes and with higher levels in boys than in girls during all Tanner stages (Fig. 2). Independent of age, sex, and puberty, there was a significant negative association of CT with $\mathrm{P}(\beta=$ $\left.-0.26^{* * *}\right)$ and height SDS $\left(\beta=-0.06^{* * *}\right)$ and a significant positive association with $\mathrm{Ca}\left(\beta=0.26^{* * *}\right)$.

\section{Discussion}

To the best of our knowledge, this is the first study to investigate correlations between CT and potential CT-associated hormones and biomarkers in an age-, sex- and puberty-dependent manner, evaluating the associations over a broad age range from 2 month to 18 years, with a large number of observations $(n=5,410)$ and the use of a high-sensitive immunoassay for measuring CT developed after 2010.

Our results present a positive relationship between $\mathrm{Ca}$ and CT in periods of rapid bone growth in the first year of life and during puberty. Therefore, this relationship is clearly age-related. Our data also indicate that CT could be associated with processes of bone formation but only in children aged 2 months- 1.1 years. As published recently [21], CT levels showed a clear age and gender dependence with maximal levels in the first year of life and significantly higher values in boys $(p<0.01)$. An accelerated decline of CT levels from newborns to children at the age of 4 and 5 years was observed for both sexes. Therefore, we examined age group data separately, first by univariate correlations and then by multiple regression analysis to enable indirect assumptions from statistical correlations to potential physiological processes.

\section{C-Cell Hyperplasia and CT}

In general, CT may be elevated because of an increased number of C-cell in the thyroid. The higher CT concentration observed in boys may be explained by the higher $\mathrm{C}$-cell density similar to that seen in men with higher CT levels [26] and higher C-cell density than in women [27]. There are only few references that estimate the C-cell density in children. In normal neonatal human thyroid glands the number of C-cells and the CT content were 10 times those observed in normal adult thyroid gland [28]. This might be a clue to the higher levels of CT in children and the sex-related differences. An increase in size and number of C cells is called C-cell hyperplasia, seen in different clinical conditions: neoplastic C-cell hyperplasia precedes and accompanies MTC in MEN2 and is associated with increased CT level; physiological C-cell hyperplasia has been described in association with a great variety of pathological conditions, for example, autoimmune thyroiditis, thyroid non-Hodgkin lymphoma, and calcium metabolism disorders [29]. The cause of C-cell hyperplasia and/or the elevated CT levels in physiological Ccell hyperplasia is unknown. 


\section{Anthropometric Parameters and CT}

The finding that premature or newborn babies have elevated serum CT levels [30-33] suggests an association of CT with anthropometric parameters of bone growth, especially in the age group of 2 months- 1.1 years. This hypothesis is supported by a positive correlation between height SDS but also BMI-SDS and CT. However, after adjusting the data for age and sex, this association was no longer significant.

\section{Calcium Homeostasis and CT}

$\mathrm{Ca}$ and CT were positively and significantly correlated even after adjusting for age and sex in the age group 2 months-1.1 years. For this reason, we hypothesize that in periods of growth and rapid bone turnover there is a higher "CT responsiveness" [32] to changes of Ca concentration; thus, an acute increase of $\mathrm{Ca}$ level by osteolytic activity of PTH or absorption from the gut leads to an elevation of $\mathrm{CT}$, which in turn decreases the $\mathrm{Ca}$ level by inhibition of osteoclasts. By this tight oscillation of $\mathrm{Ca}$ level by PTH and CT, the maintaining of Ca homeostasis is ensured.

In periods of high demands for $\mathrm{Ca}$, for example, pregnancy, lactation, and growth, CT contributes to Ca homeostasis [34] supporting the concept of a CT-related osteoprotective role [9]. Because the bone mineral content is particularly vulnerable in these growth periods there might be a strong connection between an increase of $\mathrm{Ca}$ level and an elevation of CT to protect the bones against resorption.

In contrast, several authors described a significant negative correlation between $\mathrm{Ca}$ and $\mathrm{CT}$ in neonates at about $24 \mathrm{~h}$ of age [31, 35-37]. Others observed either no or only a poor correlation between both parameters in the newborns [38, 39]. Within these case studies, CT was measured directly after birth or in postconceptional days whereas the youngest participant of our study was approximately 2 months old. After birth when the placental transfer of Ca stops, a new balance of Ca homeostasis has to be found since the Ca level diminishes for the first 24$48 \mathrm{~h}$ before it increases slightly and then eventually levels off [40]. So, our data can barely be compared to the results described above. Studies that deal with older infants are almost completely lacking. Additionally, a missing correlation between $\mathrm{Ca}$ and $\mathrm{CT}$ in 6-12-year-old children $(n=37)$ has been stated already in the literature [41] and supports our findings in 6-8-year-old children. Another study that measured CT in children from birth to 16 years of age found a positive correlation $(r=0.40)$ with $\mathrm{Ca}$, but they did not appear to have considered the role of age as confounder of neither the association nor CT levels itself [11]. Our negative association between P and CT in children aged 6-8 years or 8-18 years was similar as already known from 6- to 12-year-old children [41].

In contrast to CT, PTH is released into blood circulation in states of relative hypocalcemia, and it stimulates bone to deliver $\mathrm{Ca}$ into the circulation. Consequently, PTH should be negatively correlated to $\mathrm{Ca}$ as well as to CT. Our univariate correlations in the age group 2 months- 1.1 years revealed these relationships. Nevertheless, we could not confirm this effect between CT and PTH in the multiple regression analysis and in older children. However, 6-12-year-old children demonstrated this relationship in a paper published approximately 40 years ago [41]. To represent vitamin D metabolism, we measured $25 \mathrm{OHD}$, the precursor of the fully active 1,25-dihydroxyvitamin $\mathrm{D}(1,25 \mathrm{OH} 2 \mathrm{D})$. We expected to find a negative relationship between $\mathrm{CT}$ and $25 \mathrm{OHD}$ since, contrary to CT, $1,25 \mathrm{OH} 2 \mathrm{D}$ generally increases blood calcium level via promotion of calcium absorption in the intestine and the calcium reabsorption in the kidneys.

However, as this relationship is complex because of interrelated feedback loops the correlation between these 2 parameters could be masked. In contrast, another study described a positive correlation $(r=0.80 p<0.01)$, but only in cord blood of term infants, so one can barely compare the results [30].

\section{Bone Markers and CT}

The simple correlations in children aged 2 months -1.1 years showed a positive association for the bone formation markers OC and P1NP and CT (Table 2) which was confirmed in particular after adjusting for age and sex. As the relationships of height SDS, BMI-SDS, Ca, and PTH with CT were, as mentioned above, almost exclusively detected in 2 month-1.1-year-old infants, it is not astonishing that we found comparable data also for bone markers. In general, our findings were supported by Castagna et al. [42] and some last century studies that assumed a role of CT in early bone growth and mineralization [30, 42-45] notably in the first years of life when the bone growth rate is particularly high. Others only suppose a temporal relation between skeletal growth and serum CT concentrations [33] or indicate that CT does not influence bone formation as young patients with MTC and constant high blood levels of CT do not present an abnormal bone growth [46]. The effect of CT on bone is lost after constant high levels (MTC) or prolonged administration (pharmacotherapy) by downregulation of the CT recep- 
tor, called "escape" phenomenon [47]. But this is not the case in acute changes of CT stimulated by acute $\mathrm{Ca}$ increase in blood.

Interestingly, animal models appear to be unsuited to describe the human state as they deliver contrary data: CT appears to activate a signaling pathway that inhibits bone formation [48]. Accordingly, an increased bone formation was found in mice with ablated CT and CT generelated peptide.

Previously, it was described that CT decreased bone resorption in periods of rapid growth $[3,4]$. However, we did not find a significant correlation between CT and $\mathrm{BCL}$. An explanation for this finding is that CT only heads off peaks of bone resorption.

\section{Puberty and CT}

The second important period of accelerated bone growth and therefore a potential period of a physiological $\mathrm{CT}$ action is puberty when bone formation rate increases approximately five-fold [49]. The peak growth velocity usually happens 2 years later in males (12-16 years) than in females (10-14 years) [50]. We found that CT levels decreased with advancing Tanner stages. Silva et al. [44] could support our findings by detecting a decrease of CT during puberty in a study of the early 1980s.

Due to heterogeneity of the puberty group their univariate correlations have to be interpreted with caution. Accordingly, we formed a combined model and adjusted our model for age, sex, puberty, P, and height SDS. By this tool and in line with the results of the first year of life, we found a significant positive relation between $\mathrm{Ca}$ and CT. In contrast, a recent paper with a distinctly lower number of 60 healthy adolescent girls demonstrated no relationship between Ca and CT [49]. We did not find positive associations between $\mathrm{CT}$ and bone formation markers in puberty; the correlations were even negative. This could possibly be due to puberty-related confounders (e.g., sex steroids) which may influence the correlation between $\mathrm{CT}$ and P1NP and OC.

\section{Limitation of the Study}

The major limitation of our study emerges from general restrictions of our statistical analysis. Our findings revealed only the absence or the presence of a statistical significance in regression or correlation analyses; accordingly, the study cannot prove any causal relationships between the investigated biomarkers. Although we were able to include $>100$ measurements per age group, we recommend confirming our results with a larger study cohort and children with growth or bone disorders.

\section{Conclusion}

Periods of rapid bone growth are an extremely vulnerable period for maintaining bone density and therefore they have to be strongly regulated. We found a significant positive relationship between $\mathrm{CT}$ and $\mathrm{Ca}$ which suggests an age-dependent osteoprotective role of CT. The positive correlation between $\mathrm{CT}$ and bone formation markers in the first year of life indicates a possible involvement in growth-stimulating processes.

\section{Acknowledgements}

We are very grateful to all the children who volunteered for our study as well as for the work by physicians and technical assistants of the LIFE Child study and the work by laboratory assistants of the ILM Leipzig.

\section{Statement of Ethics}

The study was designed in accordance with the Declaration of Helsinki (1964) and its later amendments. It was approved by the Ethics Committee of the University of Leipzig under registration No. 264-10-19042010. The LIFE Child study is registered with the trial number NCT02550236. All parents and subjects older than 12 years have given their informed written consent.

\section{Conflict of Interest Statement}

The authors have nothing to disclose.

\section{Funding Sources}

This publication was supported by LIFE (Leipzig Research Center for Civilization Diseases, University of Leipzig). LIFE is funded by the means of the European Union (EU), the European Social Fund (ESF), the European Regional Development Fund (ERDF) as well as the Free State of Saxony within the framework of the excellence initiative.

\section{Author Contributions}

Design of the study: J.K. and J.S. Data collection: F.E., M.G., and J.S. Data calculation: M.V. and J.S. Interpretation of the results: J.K. and J.S. Writing of the manuscript: J.S., supported by J.K. Revision of the manuscript: M.V., M.G., F.E., A.K., F.R., W.K., and J.K. Supervision of the project: W.K. 


\section{References}

1 Anast C, Arnaud CD, Rasmussen H, Tenenhouse A. Thyrocalcitonin and the response to parathyroid hormone. J Clin Invest. 1967 Jan;46(1):57-64.

2 Raue F, Scherübl H. Extracellular calcium sensitivity and voltage-dependent calcium channels in c cells. Endocr Rev. 1995 Dec; 16(6):752-64.

3 Sexton PM, Findlay DM, Martin TJ. Calcitonin. Curr Med Chem. 1999 Nov;6(11): 1067-93.

4 Findlay DM, Sexton PM. Mini reviewCalcitonin. Growth Factors. 2004 Dec;22(4): 217-24.

5 Friedman J, Raisz LG. Thyrocalcitonin: inhibitor of bone resorption in tissue culture. Science. 1965 Dec;150(3702):1465-7.

6 Chambers TJ, Magnus CJ. Calcitonin alters behaviour of isolated osteoclasts. J Pathol. 1982 Jan;136(1):27-39.

7 Martin TJ, Melick RA. The acute effects of porcine calcitonin in man. Australas Ann Med. 1969 Aug;18(3):258-63.

8 Jaeger P, Jones W, Clemens TL, Hayslett JP. Evidence that calcitonin stimulates 1,25-dihydroxyvitamin $\mathrm{D}$ production and intestinal absorption of calcium in vivo. J Clin Invest. 1986 Aug;78(2):456-61.

9 Davey RA, Findlay DM. Calcitonin: physiology or fantasy? J Bone Miner Res. 2013 May;28(5):973-9.

10 Cooper CW, Hirsch PF, Toverud SU, Munson PL. An improved method for the biological assay of thyrocalcitonin. Endocrinology. 1967 Sep;81(3):610-6.

11 Body JJ, Chanoine JP, Dumon JC, Delange F. Circulating calcitonin levels in healthy children and subjects with congenital hypothyroidism from birth to adolescence. J Clin Endocrinol Metab. 1993 Aug;77(2):565-7.

12 Hurley DL, Tiegs RD, Wahner HW, Heath H. Axial and appendicular bone mineral density in patients with long-term deficiency or excess of calcitonin. N Engl J Med. 1987 Aug;317(9):537-41.

13 Bijvoet OL, Van Der Sluys Veer J, Jansen AP. Effects of calcitonin on patients with Paget's disease, thyrotoxicosis, or hypercalcaemia. Lancet. 1968 Apr;1(7548):876-81.

14 Bayer M. Reference values of osteocalcin and procollagen type I N-propeptide plasma levels in a healthy central European population aged $0-18$ years. Osteoporos Int. $2014 \mathrm{Feb} ; 25(2): 729-36$.

15 Poulain T, Baber R, Vogel M, Pietzner D, Kirsten T, Jurkutat A, et al. The LIFE child study: a population-based perinatal and pediatric cohort in Germany. Eur J Epidemiol. 2017 Feb;32(2):145-58

16 Quante M, Hesse M, Döhnert M, Fuchs M, Hirsch C, Sergeyev E, et al. The life child study: a life course approach to disease and health. BMC Public Health. 2012 Nov; 12(1): 1021 .
17 Kromeyer-Hauschild K, Wabitsch M, Kunze D, Geller F, Geiß HC, Hesse V, et al. Perzentile für den body-mass-Index für das Kindes- und Jugendalter unter Heranziehung verschiedener deutscher Stichproben. Monatsschr Kinderheilkd. 2001 Aug; 149(8):807-18.

18 Marshall WA, Tanner JM. Variations in the pattern of pubertal changes in boys. Arch Dis Child. 1970 Feb;45(239):13-23.

19 Marshall WA, Tanner JM. Variations in pattern of pubertal changes in girls. Arch Dis Child. 1969 Jun;44(235):291-303.

20 Geserick M, Vogel M, Eckelt F, Schlingmann M, Hiemisch A, Baber R, et al. Children and adolescents with obesity have reduced serum bone turnover markers and 25-hydroxyvitamin D but increased parathyroid hormone concentrations: results derived from new pediatric reference ranges. Bone. 2020 Dec;132:115124.

21 Eckelt F, Vogel M, Geserick M, Kirsten T, Bae YJ, Baber R, et al. Calcitonin measurement in pediatrics: reference ranges are gender-dependent, validation in medullary thyroid cancer and thyroid diseases. Clin Chem Lab Med. 2019 Jul;57(8):1242-50.

22 R Core Team. R: A language and environment for statistical computing. Vienna, Austria: R Foundation for Statistical Computing; 2020. https://www.R-project.org/.

23 Bates D, Mächler M, Bolker B, Walker S. Fitting linear mixed-effects models using lme4. J Stat Soft. 2015 Oct;67(1):1-48.

24 Hothorn T, Bretz F, Westfall P. Simultaneous inference in general parametric models. Biom J. 2008 Jun;50(3):346-63.

25 Yekutieli D, Benjamini Y. The control of the false discovery rate in multiple testing under dependency. Ann Stat. 2001 Aug;29(4): 1165-88.

26 Kahaly GJ, Algeciras-Schimnich A, Davis TE, Diana T, Feldkamp J, Karger S, et al. United states and european multicenter prospective study for the analytical performance and clinical validation of a novel sensitive fully automated immunoassay for calcitonin. Clin Chem. 2017 Sep;63(9): 1489-96.

27 Guyétant S, Rousselet MC, Durigon M, Chappard D, Franc B, Guerin O, et al. Sexrelated c cell hyperplasia in the normal human thyroid: a quantitative autopsy study. J Clin Endocrinol Metab. 1997 Jan;82(1): 42-7.

28 Wolfe HJ, Delellis RA, Voelkel EF, Tashjian AH. Distribution of calcitonin-containing cells in the normal neonatal human thyroid gland: a correlation of morphology with peptide content. J Clin Endocrinol Metab. 1975 Dec;41(06):1076-81.

29 Schmid KW. Histopathology of c cells and medullary thyroid carcinoma. Recent Results Cancer Res. 2015;204:41-60.
30 Hillman LS, Rojanasathit S, Slatopolsky E, Haddad JG. Serial measurements of serum calcium, magnesium, parathyroid hormone, calcitonin, and 25-hydroxy-vitamin $\mathrm{D}$ in premature and term infants during the first week of life. Pediatr Res. 1977 Jun; 11(6):739-44.

31 Venkararaman PS, Tsang RC, Chen I-W, Sperling MA. Pathogenesis of early neonatal hypocalcemia: studies of serum calcitonin, gastrin, and plasma glucagon. J Pediatr. 1987 Apr;110(4):599-603.

32 Dincsoy MY, Tsang RC, Laskarzewski P, Ho M, Chen IW, Davis N. Serum calcitonin response to administration of calcium in newborn infants during exchange blood transfusion. J Pediatr. 1982 May;100(5):782-6.

33 Klein GL, Wadlington EL, Collins ED, Catherwood BD, Deftos LJ. Calcitonin levels in sera of infants and children: relations to age and periods of bone growth. Calcif Tissue Int. 1984 Dec;36(6):635-8.

34 MacIntyre I. The action and control of the calcium-regulating hormones. J Endocrinol Invest. 1978 Jul;1(3):277-84.

35 Bagnoli F, Bruchi S, Sardelli S, Vispi L, Buonocore G, Franchi F, et al. Calcitonin and parathyroid hormone in newborn infants with fracture of the clavicle. Calcif Tissue Int. 1984 Dec;36(4):357-60.

36 Bagnoli F, Bruchi S, Sardelli S, Buonocore G, Vispi L, Franchi F, et al. Calcium homeostasis in the first days of life in relation to feeding. Eur J Pediatr. 1985 May;144(1):414.

37 David L, Salle B, Chopard P, Grafmeyer D. Studies on circulating immunoreactive calcitonin in low birth weight infants during the first 48 hours of life. Helv Paediatr Acta. 1977 Jun;32(1):39-48.

38 Branchi M, Patriarca PL, Bordoni P. [Radioimmunologic analysis of calcitonin and parathyroid hormone in the study of calcium homeostasis in the newborn infant during the first days of life]. Pediatr Med Chir. 1982 Dec;4(6):635-8.

39 Cannarozzi DB, Canale DD, Donabedian RK. Hypercalcitoninemia in infancy. Clin Chim Acta. 1976 Feb;66(3):387-92.

40 Pitkin RM, Cruikshank DP, Schauberger CW, Reynolds WA, Williams GA, Hargis GK. Fetal calcitropic hormones and neonatal calcium homeostasis. Pediatrics. 1980 Jul;66(1):77-82.

41 Shainkin-Kerstenbaum R, Funkenstein B, Conforti A, Shani S, Berlyne GM. Serum calcitonin and blood mineral interrelationships in normal children aged six to twelve years. Pediatr Res. 1977 Feb;11(2):112-6.

42 Castagna MG, Fugazzola L, Maino F, Covelli D, Memmo S, Sestini F, et al. Reference range of serum calcitonin in pediatric population. J Clin Endocrinol Metab. 2015 May;100(5):1780-4. 
43 Morimoto S, Fukuo K, Yamamoto $\mathrm{H}$, Imanaka S, Koh E, Hironaka T, et al. Age and sex influences on urine calcitonin-like immunoreactivity in normal subjects. Endocrinol Jpn. 1986 Dec;33(6):901-4.

44 Silva OL, Becker KL, Snider RH, Moore CF, Lando HM. Urine calcitonin in normal children. Pediatr Res. 1981 Jul;15(7):1032-5.

45 Samaan NA, Anderson GD, Adam-Mayne ME. Immunoreactive calcitonin in the mother, neonate, child and adult. Am J Obstet Gynecol. 1975 Mar;121(5):622-5.
46 Raisz LG, Bingham PJ. Effect of hormones on bone development. Annu Rev Pharmacol. 1972 Apr;12(1):337-52.

47 Heersche JNM. Calcitonin effects on osteoclastic resorption: the "escape phenomenon" revisited. Bone Miner. 1992 Mar; 16(3):174-7.

48 Hoff AO, Catala-Lehnen P, Thomas PM, Priemel M, Rueger JM, Nasonkin I, et al. Increased bone mass is an unexpected phenotype associated with deletion of the calcitonin gene. J Clin Invest. 2002 Dec;110(12): 1849-57.
49 Sarra A, Karantza M, Papaefthymiou M, Soultanakis H, Papaefstathiou A, Nikolaidou $\mathrm{P}$, et al. Influence of developmental and hormonal factors on bone health in adolescent females: a cross-sectional study and review of the literature. J Pediatr Endocrinol Metab. 2013 Jan;26(3-4):239-46.

50 Busscher I, Kingma I, de Bruin R, Wapstra FH, Verkerke GJ, Veldhuizen AG. Predicting the peak growth velocity in the individual child: validation of a new growth model. Eur Spine J. 2012 Jan;21(1):71-6. 